\title{
El ciclo narrativo del cura difunto y la misa no celebrada en vida: un precedente historiográfico del siglo XVII
}

\author{
The Narrative Cicle of the Dead Priest \\ and the Mass no Celebrated when Alive: \\ A Historiographical Precedent in Seventeenth Century
}

\author{
Joan Mahiques Climent \\ Departamento de Filología Románica. Universidad de Barcelona
}

\section{RESUMEN}

Este artículo presenta un estudio y la primera edición de un capítulo de los Anales de los carmelitas descalzos de la provincia de san José en el Principado de Cataluña, escritos por fray Juan de san José (1642-1718), cuya copia autógrafa se conserva en el ms. 991 de la Biblioteca de la Universidad de Barcelona. El texto se presenta como un hecho real, documentado a través de declaraciones juradas y examinado por el clero, que se contextualiza entre los años 16771681 en la ciudad de Vic y sus alrededores. Se inserta en la tradición de los procesos sobre apariciones de ánimas del purgatorio y, en algunos aspectos, constituye un notable precedente del cuento folclórico del cura difunto que vuelve para decir una misa no celebrada en vida.

Palabras clave: Etnografía, Cataluña, Purgatorio, Voto incumplido, Misa de ultratumba.

\section{SUMMARY}

This paper presents a study and the first edition from a chapter of the Anales de los carmelitas descalzos de la provincia de san José en el Principado de Cataluña, work copied by its own author, brother John of St. Joseph (1642-1718), in University of Barcelona Library, Ms. 991. This chapter belonging to the tradition of revenants from purgatory was examined by clergy. It was taken as a true story, proven by statements under oath. The events of this case go back to the city of Vic and its surroundings in 1677-1681, by setting an important precedent of the tale of the priest's ghost who returns from the other world to say a mass forgotten or not celebrated when alive.

Key words: Ethnography, Catalonia, Purgatory, Unfulfilled Promise, Mass of the Other World.

\section{INTRODUCCIÓN}

Uno de los relatos más populares del folclore francés, sobre todo en las regiones del noroeste, tiene como protagonista a un cura difunto que se aparece con la intención de decir una misa cobrada y no celebrada en vida. Veinticuatro versiones diferentes circunscritas todas ellas al dominio de Oïl, recientemente reseñadas por Mahiques Climent (2014b), 
presentan una misa oficiada dentro de una iglesia o capilla por el espectro del cura, en presencia de un visionario que responde en la mayor parte de los casos. Sin ceñirse totalmente a esta concatenación de motivos, pero acordes en lo esencial, otras fuentes de transmisión oral o escrita desarrollan nuevas modalidades del mismo tipo narrativo ${ }^{1}$. Aunque la mayor parte de las versiones se localizan en Bretaña, su ámbito de influencia se extiende a una gran parte de la geografía de Europa y América, en lugares como Francia, Bélgica, Irlanda, la Península Ibérica, Argentina, Estados Unidos y Canadá2. Dentro del conjunto de reelaboraciones y transformaciones que nos hablan de la difusión de este argumento, el pilar más estable y recurrente lo compone la figura del cura difunto cuya condena póstuma solamente podrá saldarse con la ayuda de algún vivo. Se trata de un elemento constituyente que desvela todo un mundo de creencias y tradiciones populares, tal como evidenciaba Paul Sébillot a través de diversos ejemplos ${ }^{3}$ :

Un assez grand nombre de légendes parlent de prêtres revenants: à Saint-Cast un ancien vicaire se promenait la nuit en chantant sur les Mielles; près du château de Biennassis un autre lisait son bréviaire dans l'allée des Chênoliaux; j'ai entendu citer bien d'autres endroits où avaient lieu de semblables apparitions; ces prêtres sont condamnés à une pénitence posthume, en raison des péchés commis pendant leur vie, et surtout parce qu'ils n'ont pas dit les messes qui leur avaient été payées (Sébillot 1900: 47-48).

Precisamente de la mano de Paul Sébillot nos ha llegado la noticia de diversos sucesos que podemos sospechar que se divulgaron en los siglos XVIII-XIX como faits divers de última hora. Es el caso de un obrero de Lamballe que, habiéndose quedado dormido dentro de la iglesia, afirmaba haber respondido a la misa de un cura que se le apareció desde el otro mundo y le confesó haber estado veinte años intentando

\footnotetext{
${ }^{1}$ Reproducen el motivo del cura difunto y la misa no celebrada algunas de las versiones clasificadas bajo el epígrafe "Mass of the Dead" por Uther (2004: I, 437, núm. 779F*), que a su vez remite a otras entradas del Motif-Index of Folk-Literature de Thompson ([1932-1936] 1966: II, 462 y 424): "E492. Mass (church service) of the dead. Held ad midnight"; "E242. Ghosts punish intruders into mass (procession) of ghosts". Las figuras del muerto agradecido y el cura difunto son representadas por un único personaje en numerosas versiones hispánicas del tipo 506*, descrito por Uther (2004: I, 291, "Prophecy Escaped") y Camarena y Chevalier (1995: 395-398, "Profecía eludida").

${ }^{2}$ De las diecinueve versiones documentadas en la Francia continental por Mahiques Climent (2014b), ocho se circunscriben a Bretaña, tres a los Países del Loira y otras tres a la Baja Normandía. Sobre las versiones hispánicas, ya sea en la Península Ibérica o en América, véase el catálogo de Camarena y Chevalier (2003: III, 123-124, núm. 760D, "El monaguillo del ánima del cura"), que remite al sistema de clasificación del Motif-Index de Thompson ([1932-1936] 1966: II, 443; V, 244): «E415.3. Ghost of priest cannot rest because he failed to say certain masses for the dead"; "Q.521.6. Penance: holding midnight mass until somenone will make responses". Nótese que una parte considerable del corpus adscrito al tipo 760D coincide con el que encontramos en Camarena y Chevalier (1995: 395-398, núm. 506*, "Profecía eludida"; 2003: IV, 393-394, núm. 934B, "El joven que había de morir el día de su boda"). Otros ejemplos que van más allá del área geográfica de las lenguas románicas son reseñados en la mencionada obra de Thompson y en la de Baughman (1966: 168 y 382, núms. E415.3 y Q.521.6).

${ }^{3}$ Aparte de los ejemplos aducidos, véanse las tradiciones populares recogidas por Poulain (1997: 222), que en buena medida inciden en la memoria de los presbíteros asesinados durante la Revolución Francesa, condenados en muchos casos por haber descuidado alguna misa encomendada. Suelen errar sin reposo por caminos y bosques, mostrándose sin cabeza y con los ornamentos sacerdotales.
} 
celebrarla (La Vallée y Brion 1794: 37-39; Sébillot 1900: 49-50; Mahiques Climent 2014b). Otras veces los curas difuntos son personajes históricos perfectamente documentados, con nombres y apellidos, que de esta manera darían una forma legendaria al relato que estamos estudiando, como sucede de hecho con el obispo de Tréguier, François de la Tour, popularmente conocido como Escop-Penarstanc, cuya vida se remonta a la segunda mitad del siglo XVI. A partir de la información suministrada por FrançoisMarie Luzel, Le Men (1870-1872: 426-427) se hacía eco de ciertos rumores populares según los cuales este obispo estaba condenado a entrar en la iglesia cada medianoche y preguntar tres veces si había alguien que ayudase a misa, aunque sin encontrar respuesta. En esta leyenda, además, el difunto no parece estar condenado por misas no celebradas en vida, sino simplemente por su mala vida, y tampoco tiene la suerte de encontrar un acólito que le ayude a saldar sus deudas de ultratumba ${ }^{4}$.

Los casos mencionados hasta ahora, y los que añadiremos más adelante, ponen de manifiesto que el motivo del cura difunto con una o varias misas pendientes puede vehicularse a través de diversas formas narrativas, como exempla, cuentos y leyendas, aunque es quizás esta última modalidad la más recurrente de todas ellas, tal como puede constatarse, por ejemplo, en diversos catálogos tipológicos sobre el cuento folclórico en catalán 5 . Debemos destacar, pues, que muchas de las manifestaciones que de diversos modos remiten a este ciclo narrativo no necesariamente se insertan en el plano de la ficción, y tampoco se limitan a una mera manifestación de costumbres o de religiosidad popular, ya que algunos de sus protagonistas — tanto visionarios como aparecidos - forman parte de la memoria histórica colectiva ${ }^{6}$.

Aunque los primeros testimonios documentados remiten a la Francia del siglo XVIII, podría tratarse de una tradición más antigua según la opinión de Paul Sébillot (1907: 173-175), ya que algunos de los asuntos que fundamentan la materia de este cuento los podemos encontrar en otros textos anteriores: el eminente etnólogo bretón aduce las autoridades de san Agustín y de san Gregorio de Tours para mostrar que la creencia de que los muertos retornan a las iglesias se remonta a los primeros siglos del cristianismo, y recuerda después un curioso exemplum inserto en el Kalendrier historial de la glorieuse vierge Marie de Vincent Charron (1637: 739-740), que explica cómo un diácono vio abierta la puerta principal de la iglesia y una multitud de cirios en-

\footnotetext{
${ }^{4}$ Muy notable al respecto es también el suceso legendario situado en la ciudad de Lleida y protagonizado por el capellán Marrades, que ha estudiado Lladonosa (1967). Este presbítero fue asesinado el día 14 de mayo de 1810, cuando las tropas napoleónicas acababan de tomar la ciudad. La voz popular dice que, habiendo muerto apuñalado sin poder acabar la misa que estaba oficiando, tuvo por intercesión de la Virgen del Carmen la oportunidad de volver ya difunto y celebrarla completa con la ayuda de un acólito vivo.

5 Diversas apariciones de ánimas son catalogadas bajo un único asiento de carácter heterogéneo por Pujol (1982: 48-49, núm. 760*), Oriol y Pujol (2003: 760*) y Rondcat (2014, núm. C-032). En su globalidad, Pujol vincula este grupo de relatos al ámbito de la leyenda más que al del cuento folclórico, sobre todo porque en la mayor parte de los casos indican unas coordenadas espaciales y temporales concretas.

${ }^{6}$ Más de un informador asegura que la misa de ultratumba no es una mera superstición, sino una realidad de la cual él puede dar fe. Véase, por ejemplo, la historia sobre la "peineuse messe" referida por La Garde (1858: 135-149). Otra fuente de carácter estadístico advierte: “Il n'est pas rare de voir des sacristes qui prétendent avoir répondu et servi à minuit de ces sortes d'offices nocturnes" (Annuaire 1909: 100).
} 
cendidos dentro, a donde los difuntos del cementerio habían entrado ${ }^{7}$. Todos estos precedentes ilustran o prefiguran el escenario de la misa de ultratumba, pero nada aportan en relación a la colaboración entre el cura difunto y el visionario acólito, y tampoco explicitan el pecado de negligencia que motiva tal encuentro.

En cambio, este pecado de omisión sí está asociado al tema de las apariciones de ultratumba en algunos exempla medievales, tal como hemos comprobado al consultar la base de datos ThEMA (2014), que remite directamente a Tubach ([1969] 1981: 250, núm. 3215): "Mass for dead neglected. A Cistercian monk suffers in purgatory for neglecting services for the dead ${ }^{8}$. Estaríamos, pues, ante diversas anécdotas moralizantes sobre clérigos difuntos — sobre todo monjes- que vuelven a este mundo no para celebrar una o varias misas pendientes sino para advertir que los sufragios aplicados por ellos no les están beneficiando sino a otros por los que ellos, en vida, tendrían que haber llevado a cabo determinadas obligaciones incumplidas, sobre todo misas.

Evidentemente, todas estas narraciones solamente se ciñen en parte al conjunto de motivos que constituyen el argumento básico, común a la mayor parte de testimonios sobre el cura difunto y la misa no celebrada en vida. Esta misma afirmación podría extenderse al relato que centrará nuestra atención a partir de ahora, esto es el proceso sobre la aparición de Sebastián Roquer, pero nos atreveríamos a decir que este último es el precedente más notable, no solamente porque su extensión permite el desarrollo de muchos de los elementos que en otras versiones se encuentran de manera aislada y parcial, sino también porque, más allá de su carácter ejemplar, se presenta como un documento histórico minuciosamente examinado por autoridades clericales, hecho que nos permite vincularlo al plano de la realidad. El relato de Sebastián Roquer podría compararse en este último aspecto a algunas leyendas locales o anécdotas presuntamente verídicas, como son la historia del obispo de Tréguier y la del obrero de Lamballe.

\section{LA APARICIÓN DE SEBASTIÁN ROQUER}

Sebastián Roquer era un joven sacerdote secular del obispado de Vic. Murió el día 31 de enero de 1677 y, al cabo de tres años, en 1680, se apareció a su sobrino Bernardino. Conocemos estos sucesos a través de dos versiones inéditas, copiadas en

\footnotetext{
${ }^{7}$ Nosotros hemos encontrado una versión catalana copiada en los fols. $1^{\mathrm{v}}-2^{\mathrm{v}}$ del ms. 61 de la Biblioteca de la Universidad de Barcelona (cf. Miquel Rosell 1958: I, 62-63; MCEM 2012, Id 1360). Que diversos autores conocían y compilaron este caso lo refiere el ms. 61, que al final del relato indica explícitamente: "Este exemple lo refereix Enrique Teutònico, distinctione 3, cap. 64; y Berlarmino, fol. 39".

${ }^{8}$ Entre los exempla que ThEMA (2014) asocia a esta entrada del catálogo de Tubach, nos interesan especialmente dos pasajes del Collectanevm exemplorvm et visionvm Clarevallense (Legendre 2005: 259 y 370-371, núms. 71 y 161); y uno del Tractatus de diversis materiis predicabilibus de Stephanus de Borbone (2002: 179, líneas 1162-1166; 456, núm. 181). Otros casos similares se localizan en el Liber de introductione loquendi (liber v, cap. 52) de Filippo da Ferrara y en un manuscrito de la British Library (ms. Add. 27909 B, fol. 4, núm. 6). Todos estos textos pueden datarse entre la segunda mitad del siglo XII y la primera mitad del siglo XIV, según la cronología indicada en ThEMA (2014).
} 
dos manuscritos del siglo XVIII que pertenecen a la Biblioteca de la Universidad de Barcelona (a partir de ahora, BUB). El ms. 326 transmite una copia de la relación que en 1691 escribió fray Segismundo del Espíritu Santo (1642-1706) después de haber interrogado directamente a algunos testigos presentes durante las apariciones. Sin duda, se inspira en este documento la versión que fray Juan de san José (1642-1718) inserta en sus Annales de los carmelitas descalços de la provincia de san Josef en el Principado de Cathaluña, cuya copia autógrafa se conserva en el ms. 991 de la BUB'. La redacción del ms. 326 es mucho más pormenorizada, ya que su extensión triplica a la del relato de fray Juan de san José. De todos modos, los Annales desarrollan una versión bastante detallada, en la que no falta ninguno de los elementos necesarios para fundamentar el estudio que ahora estamos abordando. Teniendo en cuenta este último aspecto y considerando que ambas fuentes son inéditas, hemos preferido basar nuestro análisis en el ms. 991, cuyo texto editaremos al final de este artículo incorporando en nota, oportunamente, cualquier referencia a la relación de fray Segismundo del Espíritu Santo. El ms. 991 tiene un colofón escrito en Mataró el 8 de agosto de 1707, aunque su autor comenzó a trabajar en este proyecto historiográfico en el año 1695 (Arnall Juan 1986: 90). Este volumen divide el contenido de los Annales en seis libros. El pasaje que ahora nos ocupa se localiza en capítulo LI del libro IV y relata los hechos que resumiremos a continuación, indicando los números de párrafo que figuran tanto en el manuscrito como en la edición que añadiremos al final de este artículo:

1254. Tiene el convento de carmelitas de Vic un lienzo con cinco cruces de fuego que dejó impresas el ánima de Sebastián Roquer. 1255. Murió el 31 de enero de 1677, en la parroquia de santa María de Alpens, a los tres meses de ser sacerdote. Tres años después, pocos días antes de la conmemoración de los difuntos, comenzaron a caer piedras a la puerta, al tejado y otros sitios, estando en casa el padre, la madre, un hermano casado y el sobrino del difunto. 1256. Durante ocho días se repitieron las pedradas y sus familiares, persuadidos de ser aquello cosa del otro mundo, lo explicaron al cura del lugar. El rumor se extendió y la casa se llenó de curiosos. Pasaron tres días sin pedradas y, al día siguiente y al otro, Bernardino, de siete años, sobrino del difunto, lo vio sentado en un escaño de la cocina sin saber todavía que era él. Sospechándolo los padres de Sebastián, persuadieron a Bernardino a ir a la planta superior de la casa para que, si se le volvía a aparecer, preguntase qué quería. El difunto se apareció y pidió siete misas, más medio año de una ofrenda que debía ser en la iglesia donde estaba enterrado su cuerpo. A partir de entonces y hasta el final, el difunto se aparecerá solamente a Bernardino. 1257. El muchacho se equivocó al referir a sus abuelos la demanda del difunto y, en lugar de siete misas, dijo que eran dos. Ellos dudaron, que no fuese enredo del demonio, pero se disipó la incertidumbre con una nueva aparición, en la que Sebastián

${ }^{9}$ Los mss. 326 y 991 han sido descritos por Miquel Rosell (1958: 420-421 y 564-565) y por nosotros mismos en MCEM (2012, Id 1925 y 1166). Ambas fuentes divergen al transcribir el apellido del difunto, que en la primera es llamado "Roquer" y en la segunda "Roquero". Adviértase, además, que el ms. 991 coincide, desde su inicio hasta la p. 185 de la BUB, otro autógrafo de fray Juan de san José, cuyo título es el siguiente: Historia de la provincia de san Joseph de los carmelitas descalços en el Principado de Cathaluña. Los acontecimientos que ahora estamos estudiando, referentes a las apariciones de Sebastián Roquer, solamente se incluyen en el ms. 991, pero otras efemérides con apariciones de difuntos han motivado un análisis comparativo de ambas fuentes con la consiguiente edición sinóptica de sus respectivas redacciones (Mahiques Climent 2014a; 2016). 
aseguraba que se le aparecería al visionario por el camino (especialmente en todas las cruces) durante el viaje para la celebración de las misas, y que en cada una de ellas, al levantar el oficiante la Hostia, le vería en el altar. Emprendieron el viaje, y todo sucedió como prescribió el aparecido, que los acompañaba vestido como para decir misa. 1258. Los familiares celebraron las dos misas, encomendaron a una persona que continuase la ofrenda de medio año y volvieron a su casa pensando haber cumplido con todo, pero el difunto volvió a aparecerse a Bernardino para decirle que faltaban cinco misas, y que la ofrenda debía hacerla su propia madre. 1259. La madre hizo la ofrenda en la iglesia del pueblo, y otro la hizo en Vic, pero el difunto se apareció advirtiendo que cuanto habían hecho no valía. Unas veces iba vestido con sobrepelliz y otras con casulla. Ante las dudas de la madre y otros familiares, se apareció e hizo varias señales, algunas de las cuales quedaron impresas en un lienzo. 1260. Al final decidieron cumplir con todo lo que pedía el difunto, y emprendieron el viaje. Por el camino, Bernardino veía cómo el aparecido les acompañaba vestido como para decir misa y con una vela en la mano. Cuando el medio año de la ofrenda ya estaba muy adelantado, se apareció acompañado de cuatro ángeles, dos a cada lado, en el aposento de Bernardino, con quien estuvo hablando un rato, hasta que se abrió el techo y el difunto y los ángeles subieron hacia el cielo. Según comentó en aquella ocasión, antes de aparecerse había sufrido tres años de purgatorio por haber recibido la limosna de tres misas que no había celebrado en vida. 1261. El penúltimo día de la ofrenda, coincidiendo con Pentecostés, Bernardino pidió que le despertasen tres horas antes del amanecer. Vio dos velas encendidas en su aposento. Y el último día, toda la familia fue hasta el Portal de Malloles, en Vic, donde Bernardino vio a Sebastián en lo alto de la cruz, alegre, revestido con sus ornamentos sacerdotales y con una capa pluvial, acompañado de cuatro ángeles, con velas en las manos. El difunto bendijo a sus familiares, y empezó a subir hacia el cielo. 1262. Un carmelita descalzo examinó este caso, interrogando a Josep Roquer, hermano del difunto, y haciéndole declarar bajo juramento.

Que Sebastián Roquer sea un sacerdote secular concuerda con la casi totalidad de las versiones del cuento del cura difunto y la misa no celebrada en vida, aunque, sin duda, se trata de una excepción en el conjunto de las apariciones incorporadas a los Annales de fray Juan de san José, donde espectros y visionarios suelen pertenecer a la orden de carmelitas descalzos, como de hecho sucede en el ejemplo estudiado por Mahiques Climent (2016). De esta manera, la excepcionalidad del caso de Sebastián Roquer en el contexto de los Annales podría explicarse a partir de su configuración según los paradigmas culturales que también sustentan el ciclo narrativo que está centrando la atención de este artículo. Veamos a continuación algunos de los paralelismos más significativos. El pecado cometido por Sebastián consiste en haber cobrado tres misas encomendadas para unos días concretos, pero estas no se celebraron en tales fechas y él murió antes de haber cumplido con el encargo ( $\$ 1260$ ). Por eso se aparecía reiteradamente a Bernardino, también durante las dos peregrinaciones encaminadas a celebrar el sacrificio eucarístico, acompañando de este modo a sus familiares, vestido de sus ornamentos sacerdotales y con una vela en la mano que encendía cuando encontraban una cruz en el camino. También asistió a las misas aplicadas en sufragio suyo, mostrándose a Bernardino en el altar justo al levantar la Hostia, de manera que podríamos decir que estas eran concelebradas al mismo tiempo por el difunto y por el cura a quien los familiares las encargaron ( $\$ 1257$ y 1260).

Ahora volvamos a revisar algunas de las versiones relativas al ánima del cura y la misa no celebrada en vida. Curiosamente, el obrero de Lamballe que presuntamente había servido en una misa de ultratumba aseguraba haber visto a un cura de descar- 
nadas mejillas que salía de la sacristía con hábito sacerdotal y llevando un cirio en la mano (La Vallée y Brion 1794: 37-39) ${ }^{10}$. Aunque prácticamente todas las versiones de este ciclo mencionan las vestiduras que identifican al difunto como sacerdote, la referencia al cirio en la mano es menos usual. De hecho, este último elemento parece más ligado a las apariciones colectivas y procesionales, donde, por cierto, no es infrecuente la convivencia entre vivos y muertos. Un ejemplo ilustrativo lo podríamos encontrar en la parodia representada en el capítulo XIX de la primera parte del Quijote, aunque en este sentido tienen mayor relevancia las diversas representaciones de la Santa Compaña, tradición circunscrita predominantemente a la cultura gallega ${ }^{11}$. El ánima de Sebastián Roquer y los familiares a los que acompaña vendrían a formar un grupo de peregrinos que hasta cierto punto sería comparable al de apariciones procesionales como las que acabamos de mencionar. De todos modos, otras fuentes de tradición oral o escrita remiten más claramente a la misma situación de los dos viajes referidos en los Annales de fray Juan de san José.

Nos centraremos ahora en el tema del recorrido que debe realizar un difunto para cumplir con alguna misa o algún otro voto prometido en vida. En el año 1878, en la localidad picarda de Warloy-Baillon, fue registrada la narración cuyo elocuente título reza: Le revenant qui se fait porter à Notre-Dame (Carnoy 1883: 115-119). Esta historia explica cómo la hija de un campesino, habiendo hecho el voto de peregrinar con su padre a Notre-Dame de Brebières, murió antes de poderlo realizar, por lo que se apareció a su padre y le pidió que la sacase de la tumba y la llevase a aquella iglesia para cumplir de este modo con lo prometido. Pero el visionario estaba poco dispuesto a secundar este deseo, y solamente accedería a satisfacer el encargo después de una insistente sucesión de apariciones que lo habían dejado cada vez más amedrentado. Así que, una noche, el hombre cargó con su hija a la espalda y, cuando llegaron a la iglesia, la puerta se abrió sola. Dentro estaba un cura difunto preparado para celebrar la misa. Respondieron como acólitos a la misa un muchacho del coro y la difunta, que aseguró a su padre que iría a la gloria celestial y que no volvería a

\footnotetext{
${ }^{10}$ Compárese esta descripción del aparecido con la que retrae Isabel Branes, la criada de la familia del difunto en un proceso acaecido en Manresa en el año 1599: "Vi mu[y] distinctament[e] un bulto en forma y figura de un hombre amo[r]tajado que solament[e] se le podía ver la cara, las manos y los p[ies], y traýa un libro en la mano izquierda y una redoma y u[na] candela encendida" (Archivo de la Casa de Alba, caja 124, núm. 320, fol. $1^{\text {v }}$ ).

${ }^{11}$ Nótense algunas semejanzas: "La compaña es la reunión de almas del purgatorio para un fin determinado. A las doce de la noche se levantan los difuntos, salen en procesión por la puerta principal, una persona viva va delante con la cruz y el caldero del agua bendita, y no puede, bajo ningún pretexto, volver la cabeza. Cada difunto lleva una luz que no se ve, pero se percibe claramente el olor de la cera que arde. La comitiva tampoco se ve, pero se percibe el airecillo que produce su paso. El desgraciado director sólo puede dispensarse de tan tétrico cometido, encontrando á otra persona y entregándole la cruz y el caldero, antes de que haga un círculo en la tierra, con lo cual queda libre de dirigir la compaña. Estas procesiones suelen terminar frente a la casa de un vecino, cuya muerte anuncian tirando piedras sobre su tejado" (Rodríguez López 1910: 187-188). Sobre el episodio cervantino y su relación con el tema de las apariciones de ultratumba, remitimos a Redondo (1997: 116-117) y Mahiques Climent (2008: 71-72). El caso de la Santa Compaña, el pasaje del Quijote y otras procesiones de ultratumba con cirios en la mano son comentadas por Lisón Tolosana (2004: 23-24, 36 y 40-41). Compárense estos testimonios con el tipo de relato descrito por Camarena y Chevalier (2003: III, 319-320, núm. 836G, "La curiosa y la vela convertida en hueso").
} 
aparecérsele nunca más. Esta historia coincide con la de Sebastián Roquer no solamente por el hecho de presentar una peregrinación compartida entre los familiares todavía vivos y el difunto por quien se aplican los sufragios, sino porque la primera de las dos partes constituyentes incurre en un caso de flagrante negligencia. Lo mismo sucede en el relato de la aparición de Pedro Codorniu, que fray Juan de san José refiere en el capítulo XX del libro IV de sus Annales. En un breve diálogo con la visionaria, una criada de la casa, el difunto le da las siguientes instrucciones:

Dirás a mi hija Mariana Cuyás que vaya a Nuestra Señora de Monserrate a pie descalço, y a la hermita de san Cyprián, que está cerca de aquí en la parrochia de Orta, porque un día, baxando yo la montaña de san Gerónimo, me vi en gran peligro de ladrones. Y como yo traýa dos doblones y algunos reales, prometí a Dios nuestro señor que si me librava de los ladrones — que ni me hurtaran ni me hizieran daño- haría essas dos romerías. Y después de averme Dios librado, no cumplí con lo prometido, de que he padecido mucho en el purgatorio (BUB, ms. 991, p. 328, $₫ 1050$ ).

Por lo menos inicialmente, los familiares de Pedro Codorniu no alcanzan a satisfacer la voluntad del difunto. En efecto, Mariana Cuyás cumple solamente con la romería de san Cipriano, y no con las debidas circunstancias, por lo que su padre vuelve a aparecerse a la criada, reiterando la obligación de hacer las dos romerías, primero la de Montserrat y después la de san Cipriano, puntualizando que esta última debía repetirse porque la primera vez no se había efectuado satisfactoriamente ni se había dicho la misa aún. Además, el difunto asegura a la visionaria que él se le mostrará y los acompañará durante el camino que deben andar. Entonces, la reacción de la familia es inmediata:

Con esto, no se lo tuvieron a burlas, emprendiendo la romería de Monserrate con toda devoción. La criada vio todo el camino el alma que iva delante sin tocar en tierra hasta que entraron en la villa de Martorell, que se desapareció hasta que bolvieron a salir. Llegados a Monserrate, se dixo la missa por el difunto, el qual asistió a ella hasta la fin con muestras de gran contentamiento (BUB, ms. 991, p. 329a , \ 1051).

Saltan, pues, a la vista los paralelismos que presenta este relato con el de Sebastián Roquer, no solamente por referir el incumplimiento de los sufragios encargados a los familiares, sino también por representar una peregrinación en la que estos son acompañados por el difunto.

Los ejemplos que hemos ido señalando nos permiten observar que el ciclo narrativo del cura difunto y la misa pendiente representa de maneras diversas el encuentro entre el visionario y el aparecido. Unas veces el encuentro se produce inesperadamente dentro de un templo sagrado, coincidiendo con el momento del sacrificio eucarístico. En cambio, otros testimonios desarrollan una peripecia notablemente distinta en la que, a sabiendas, el visionario decide asistir a la misa de ultratumba, en unos casos porque es citado previamente por el difunto o por otro personaje, y en otros casos porque encarna la figura del valentón que, resolviendo el misterio de la iglesia o la casa encantada, devolverá la quietud a toda una población aterrorizada por tales sucesos paranormales ${ }^{12}$. No cabe duda de que la historia de Sebastián Roquer

${ }^{12}$ Recrean el tópico del valentón encargado de resolver el misterio diversos cuentos populares hispánicos, reseñados en su mayor parte por Camarena y Chevalier (2003: III, 123-124, 
se relaciona más claramente con la primera variante de esta última modalidad, es decir, el grupo de relatos en los que el visionario cumple deliberadamente con el cometido que se le ha encomendado, no por un arranque de valentía sino por pura obligación.

Otro elemento que merecería una cierta atención es la representación del cura difunto en el momento en que ha cumplido su penitencia. Poco antes de subir definitivamente a la gloria celestial, Sebastián tiene una conversación con Bernardino en su aposento, que podría equipararse a la que aparecido y visionario entablan en muchas versiones del ciclo estudiado, sobre todo en la escena que sigue al final de la misa (Mahiques Climent 2014b). Pocos días después de este suceso, en el Portal de Malloles de la ciudad de Vic, se produce la última despedida de Sebastián, apareciéndose en una visión con claros indicios de gloria, bendiciendo a toda su familia y elevándose hacia el cielo, custodiado por cuatro ángeles (\$ 1260-1261). Esta descripción concuerda parcialmente con la que encontramos al final de Le gantier de la rue Baudrière (De Soland 1858; Sébillot 1907: 176-177): el cura desaparece justo al pronunciar "Requiescat in pace", y entonces el guantero contempla cómo dos formas blancas y luminosas se elevan hacia el cielo $^{13}$.

Este capítulo que los Annales de fray Juan de san José dedican a Sebastián Roquer comparte diversos elementos con otros relatos sobre apariciones, ya sean de transmisión oral o escrita, ya sean de carácter moralizante, historiográfico o documental. Esto nos ha permitido esbozar un panorama complejo tanto a nivel diacrónico como sincrónico, con una rica trama de conexiones e influencias entre diversos textos de temática similar, aunque de diversas épocas y tradiciones lingüísticas. Dentro de este mosaico de relaciones y significados, la historia de este sacerdote de la diócesis de Vic se nos presenta como un testimonio de una gran densidad cultural y un destacado precursor del relato del cura difunto y la misa no celebrada en vida, tal como lo conocemos a través de sus múltiples versiones folclóricas.

\section{CONCLUSIONES}

El ciclo narrativo del ánima del cura que vuelve para celebrar una misa pendiente responde a la idea, reiterada en numerosos relatos sobre apariciones de difuntos, de

núm. 760D, "El monaguillo del ánima del cura"). Remitimos, por ejemplo, a Amades (1950-1969: I, 1160-1161, núm. 1627, La missa de sant Miquel de Montserrat; III, 500, La missa no celebrada), Coll (2001: 60-61, Qui m'ajudarà la missa...?), Cabal (1921: 84-88, El soldado valeroso), Espinosa (1946: 130-131, núm. 71, El alma del cura), Jiménez Romero (1990: 68-69, núm. 16, La iglesia encendida) y Oliveira (1905: 204-208, núm. 288, O raio apanhado). Nótese que la figura del valentón no es propia de los testimonios que vehiculan el tema del cura difunto y la misa pendiente en forma de hecho legendario o suceso presuntamente verídico.

${ }_{13}$ Otra variante casi idéntica la constituye La cathédrale (Fouquet 1857: 106-111; cf. Sébillot 1907: 176-177). Por otra parte, La messe d'une heure (Sauvage 1869: 109-111, núm. XXI) se asemeja hasta cierto punto a los casos anteriores: al final la figura del cura difunto se vuelve vaporosa, se disipa sobre el altar y sube al cielo mientras dice: "Merci! Merci! - Je suis sauvé". Todos estos relatos, y también Le gantier de la rue Baudrière, se incluyen en las veinticuatro versiones reseñadas en Mahiques Climent (2014b). De todos modos, estas gloriosas ascensiones aparecen también en otros relatos sobre vidas santas o venerables. 
que es necesario saldar las deudas contraídas en este mundo para encontrar el reposo eterno y entrar en la gloria celestial. No es extraño, pues, que algunos exempla medievales sobre ánimas en pena amonesten a los presbíteros para que cumplan escrupulosamente los compromisos asumidos en materia de sufragios. El relato de Sebastián Roquer retoma esta tradición, pero añade un elemento constituyente fundamental en la configuración de las versiones folclóricas tal como serán documentadas desde finales del siglo XVIII hasta la actualidad. En efecto, la relación de fray Segismundo del Espíritu Santo y la reescritura historiográfica de fray Juan de san José representan al difunto revestido con los ornamentos sacerdotales, celebrando las misas que le servirán para saldar su deuda de ultratumba. Conocida a través de los mencionados carmelitas descalzos de Cataluña, esta historia reproduce diversos motivos inéditos hasta entonces en los antecedentes que prefiguran el ciclo narrativo ahora estudiado. Motivos que, sin embargo, hemos documentado en fechas posteriores, sobre todo en el noroeste de Francia, donde este relato es recreado no pocas veces en forma de leyenda local. El texto catalán destaca por describir la misa de ultratumba no como un hecho inesperado para el visionario, sino como un precepto exigido primero por el ánima en pena y después planificado por los vivientes más allegados, que acaban cumpliendo en todo lo requerido. Entre otras cosas, llevan a cabo una peregrinación en la que son acompañados en todo momento por el difunto. Si las versiones hispánicas tienden a situar el primer encuentro entre cura y visionario dentro de un recinto sagrado, muchos de los testimonios franceses que hemos examinado representan al difunto apareciéndose personalmente al visionario, o en su habitación o en un espacio abierto, dando entrada, más esporádicamente, al tema de la peregrinación compartida. Estos aspectos concuerdan notablemente con la relación de Sebastián Roquer.

Claro está que este relato historiográfico, presuntamente verídico, enmarcado en las inmediaciones de la ciudad de Vic entre los años 1677-1681, constituye un precursor todavía muy incipiente, que no puede adscribirse a ninguno de los argumentos tipológicos característicos del ciclo narrativo tal como nos ha llegado a través de la tradición folclórica contemporánea. Debe notarse la particularidad de que Sebastián Roquer se limite a concelebrar la misa juntamente con otros presbíteros que todavía pertenecen al mundo de los vivos, hecho absolutamente insólito en todas las demás versiones que hemos consultado. Además, el presbítero catalán en ningún momento exige al pequeño Bernardino, único visionario de las apariciones de ultratumba, que haga de acólito durante la misa, si bien en otros pasajes el muchacho cumple con otras funciones que la tradición adscribe al monaguillo ayudante del cura difunto. El análisis narratológico de la historia de Sebastián Roquer también nos lleva a concluir que las versiones posteriores no pueden derivar de este relato catalán, pero sí que comparten una pauta narrativa común —una estructura profunda preexistente- que se sustenta en el mismo motivo central, eso es el cura difunto y la misa no celebrada en vida.

\section{EDICIÓN DEL TEXTO}

Antes de pasar a la transcripción del texto propiamente dicho, hemos establecido los criterios que regirán nuestra edición del capítulo li del libro IV de los Annales de 
fray Juan de san José, tal como son copiados en el ms. 991 de la BUB. Estos mismos criterios son los que hemos seguido al citar diversas fuentes antiguas en las páginas precedentes, y también nos ceñiremos a ellos en otras citas de otras fuentes primarias. Hemos intentado mantener al máximo las soluciones gráficas del testimonio original, pero seguimos la ortografía actual en la acentuación, la puntuación, la separación de palabras y el uso de mayúsculas y minúsculas. Solamente hemos regularizado las grafías en las alternacias $u / v, i / j$ y $y / j$, y marcamos con el apóstrofo algunas elisiones no contempladas por la normativa actual. Mantenemos la numeración de párrafos del original, y marcamos en cursiva y entre comillas las intervenciones de algunos personajes en estilo directo. Indicamos con una barra los saltos de página o de folio, senalando en superíndice la paginación manuscrita. Los fragmentos manuscritos espurios o indebidamente repetidos han sido marcados entre $<>$, mientras que añadimos entre [ ] el texto que no figura en la fuente original. En el aparato de notas, nos hemos limitado a indicar algunos aspectos eludiendo en todo caso la repetición de la información que hemos señalado en las páginas precedentes.

[Biblioteca de la Universidad de Barcelona, ms. 991, pp. 3975-400 , libro IV, cap. LI, \1254-1262]

\author{
| $397 \mathrm{~b}$ Capítulo LI \\ Refiérese un caso moderno de una ánima del purgatorio \\ que puede ser de edificación y provecho
}

1254. Tiene este convento un lienço señalado con unas cruzes de fuego que dexó en él impressas una ánima del purgatorio. Y porque fue harto extraordinario el caso y puede ser de enseñança maiormente para los sacerdotes y prelados, lo referiré aquí abreviando las muchas circunstancias que le acompañaron.

1255. En la parrochia de Santa María de Pens, distante de la ciudad de Vique tres leguas, vivía un virtuoso sacerdote llamado el licenciado Sebastián Roquero, hijo de padres pobres ${ }^{14}$. El padre se llamava Bernardo y la madre Estasia. Murió el buen sacerdote asistido de nuestros religiosos (después de tres meses que lo era) no en su parrochia, sino en una casa extramuros de la ciudad de Vique llamada el Molino de Domènech. Murió muy religiosamente, recibidos todos los santos sacramentos con mucha devoción el día último de enero del año 1677. Al cabo de tres años, que fue el año 80, se apareció en la forma siguiente ${ }^{15}$. Estando algunos días antes de la commemoración solemne de todos los difuntos el padre, la madre, un hermano casado y un sobrinito del difunto en la casa en que vivían en la dicha parrochia de Pens, enpeçaron a tirar piedras a la puerta y al texado de la casa $^{16}$. Asustáronse, aunque no podían atinar de dónde venían las pedradas. La víspe-

\footnotetext{
${ }^{14} \mathrm{El} \mathrm{lugar}$ referido debe identificarse actualmente con la parroquia del municipio de Alpens.

${ }^{15}$ Adviértase que, como se indica más adelante, cada año de purgatorio se correspondería a una de las tres misas negligidas en vida del difunto $(\$ 1260)$.

${ }^{16}$ El motivo de las piedras es común en diversos relatos de aparecidos. Lo encontramos en un fragmento de Rodríguez López (1910: 187-188) sobre la Santa Compaña que ya hemos citado antes, y también en otros dos pasajes de los Annales de fray Juan de san José, el primero de los cuales relata las apariciones del ya mencionado Pedro Codorniu: "Echavan delante de todos ya piedras, ya ladrillos, ya grandes brasas de fuego; y algunos días que estava lluviendo, las piedras y ladrillos que tiravan estavan todos mojados pero muy calientes $\mathrm{y}$, aunque algunos davan en las cabeças, no hazían daño alguno" (BUB, ms. 991, p. 328a, \$ 1049). El segundo pasaje se refiere a fray José de la Virgen: "Aviéndose olvidado un día las devociones que les solía rezar, le despertaron por tres vezes tirándole una piedra a la ventana hasta que, acordándose que no avía
} 
ra de dicha commemoración solemne, a hora de las avemarías, bolvieron a repetirse las pedradas a la puerta, $\tan$ a menudo y tan rezias que nadie osó entrar ni salir por ella. Continuándose la batería hasta medianoche, fuéronse a dormir y luego cessó. El día siguiente, casi a la misma hora, estando al umbral de la puerta Joseph Roquero (hermano del difunto) con un hijo suyo de siete años llamado Bernardino, enpeçaron otra vez a tirar piedras como antes y, dando una d'ellas en la cabeça de Bernardino, ningún daño le hizo ${ }^{17}$. Con esta y otras circunstancias que observaron, se pe[r]suadieron era cosa del otro mundo ${ }^{18}$. Aviendo tirado otro día en[clima una mesa una piedra tan grande como la cabeça de un hombre, la llevaron al cura del lugar en tiempo que avía allí una misión y, por | ${ }^{398 a}<$ por> consiguiente, grandísimo concurso de gente, entre la qual se divulgó luego el $\mathrm{caso}^{19}$. Enpeçaron a ir a processión hecha a la casa a ver las prodigiosas pedradas. Llenose la casa de gente y por toda la mañana continuaron en ella con pedradas. Veíanlas venir por el ayre y los fuertes golpes que davan y señales que dexavan sin que dañassen a persona alguna, siendo tantas que andavan a empellones. Fuéronse todos admirados y testigos de la maravilla ${ }^{20}$.

rezado por las almas, se levantó y rezó. Y no le despertaron más, pero halló el otro día ${ }^{624 a}$ las tres piedras a la ventana" (BUB, ms. 991, pp. 623 $-624^{\mathrm{a}}, \mathbb{1}$ 1940). Dos procesos sobre apariciones reiteran este mismo tópico. En el primero, acaecido en 1599 en Manresa, la criada Isabel Branes declara: "Y assí en el mes de enero próxime pasa[do] tiraron algunas piedras en la sala de la dicha casa" (Archivo de la Casa de Alba, caja 124, núm. 320, fol. 1v). Asimismo, la Informació rebuda de la aparició $i$ visió de una ànima de certa defuncta en Pavia, del año 1623, refiere que "haurà un mes y mitx poch més o manco se comensaren a tirar alsgunes pedres devant lo pati de la porta de casa de Joan Rocha, pagès de dit lloch de Pavia, sens saber ni poder entendre de hont podien tirar-les ni qui les tirave, si bé no feyen dany a persona alguna" (Arxiu Comarcal de la Segarra, caja 28, reg. 263, fol. [1']).

${ }^{17} \mathrm{El}$ relato de fray Segismundo del Espíritu Santo no solamente omite que Bernardino sea hijo de Josep Roquer sino que también menciona al muchacho según un apellido diferente: «El sábado casi a la mesma hora, estando al umbral de la puerta de casa Joseph Roquer (hermano del difunto) y Bernardino Herra (su sobrino), se bolvieron otra vez a proseguir las pedradas como el día antecedente, de las quales dio una en la cabeza de Bernardino, el cual acudiendo luego con la mano al lugar del golpe halló que no le havía hecho mal alguno más que si fuera de

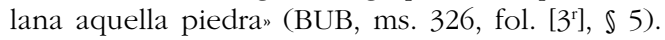

${ }^{18}$ La familia de Sebastián Roquer se determina a considerar la naturaleza sobrenatural del caso justo en el día de la conmemoración de los difuntos, es decir, el 2 de noviembre, que quizás sea la fecha más recurrente entre las señaladas en los relatos sobre el otro mundo. El visionario es un niño de siete años, dato de clara significación cultural, pues muchos de los casos de apariciones se dirigen a los más débiles y menos instruidos de la sociedad, como por ejemplo las mujeres jóvenes o viudas, las criadas y los niños. Recordemos que las visionarias son criadas en el relato de Pedro Codorniu y en el proceso de Manresa del año 1599, ya citados previamente.

${ }^{19}$ La consulta a un párroco constituye una de las maneras de mediación clerical más reiteradas en los relatos folclóricos, aunque en este caso no se determina de qué manera el sacerdote interviene en el discernimiento del caso. Sea como sea, este tipo de mediación es un recurso muy explotado en una gran diversidad de versiones del cuento del ánima del cura y la misa no celebrada en vida, tal como indica Mahiques Climent (2014b) y tal como sucede en algunos de los ejemplos que ya hemos aludido (Fouquet 1857: 106-111; De Soland 1858). Compárense también estos textos con L'ànima del moliner, El gos de foc y L'ànima del lladre, compilados por Amades (1950-1969: III, 497-498, 501 y 505).

${ }^{20}$ La relación de fray Segismundo del Espíritu Santo añade un episodio que, por su interés, transcribiremos parcialmente: "Quiso el dicho hermano del difunto hazer una prueva para ver si aquello era de buen espíritu. Y fue en una de aquellas piedras escrivió estas tres palabras: "Jesús, María, Joseph". Y hecho esto, la arrojó al rincón de un aposento, diziendo: "Ahora veamos si a esta piedra la tocarán y tirarán". Apenas dixo esto quando la arrojaron arriba a otro aposento alto que havía en la casa. Fueron a buscarla y vieron todos ser la misma piedra en que estavan escritas las dichas tres santíssimas palabras, de que todos se holgaron mucho y se firmaron más en que aquello era de Dios" (BUB, ms. 326, fol. [4], 『9). 
1256. Duró este combate de piedras por ocho días, cessando siempre a las horas de comer o cenar y dormir. Después se passaron tres días sin sentir cosa alguna. Al día siguiente, vio el sobredicho Bernardino un hombre sentado en el escaño de la cozina, donde avía sido la mayor batería de las piedras. Y como no le conociesse, preguntó a su agüela (madre que era del difunto) qué hombre era aquel que allí estava sentado. Respondiole que allí nadie avía. Replicó el muchacho: "¿Cómo no? Bien lo estoy yo mirando". Entonces se llegó la agüela a la puerta de la cozina y al mismo escaño y a nadie vio, pero el muchacho vio que, al llegar ella al escaño, se levantó el hombre y, saliéndose por la otra parte, desapareció. Al otro día, se le bolvió aparecer de la misma suerte y en el mismo lugar y, acariciándole, le alargó la mano como pidiendo alguna cosa, pero se asustó tanto el niño que, llorando y temblando, levantó el grito y el difunto desapareció. Con algunas señas que dio Bernardino, entendieron los padres que era el alma de su hijo; e hizieron mucha fuerça al muchacho para que subiera a una pieça alta de la casa, que quiçá allí a solas se le bolvería a aparecer, y que le preguntasse que qué quería ${ }^{21}$. Assí se hizo, aunque con mucha dificultad y temor del muchacho. Presto vino el alma, en la misma figura que las otras vezes. Y esforçando al muchacho para que no temiesse, le dixo estas palabras: "Di a mi padre y a mi madre que me faltan siete missas y medio año de la ofrenda, y que ese ha de ser en la iglesia donde está enterrado mi cuerpon. Y dicho esto, desapareció.

1257. Refiriéndolo el muchacho a sus agüelos, en cuenta de dezir que pedía siete missas, dixo que pedía dos. Animáronle a que bolviesse otra vez y le dixesse si avía menester otra cosa. Hízolo, y el alma le dixo que no quería otra cosa sino que fuessen tan presto como pudiessen a Vique a que le dixessen las missas en la iglesia donde le enterraron. Preguntándole más, si quería hablar con su madre, respondió que no tenía licencia para esto, pero que fuessen con toda priesa a hazer celebrar las missas que havía dicho y que enpeçaran luego el medio año de |398b la ofrenda y que avían de ir todos, sus padres y su hermano Joseph y Juan y su cuñada Escolástica y el Bernardino también. Y con esto se fue. Dio Bernardino relación de todo, aunque con la misma equivocación de las dos missas en qüenta de siete. Oyendo todo esto los padres y hermano del difunto, enpeçaron a dudar y a temer no fuesse algún enrredo del demonio que quisiese engañarles. Pero el mismo día se le bolvió apar[e]cer a Bernardino y les asseguró de la verdad, diziendo no reparassen en ninguna manera en hazer lo que les pedía; y que a él se le mostraría por el camino, especialmente en todas las cruzes que encontrarían; y que en cada missa, quando levantarían la Hostia, le vería en el altar, y en la última se quedaría en lo alto quando baxaría el sacerdote la Hostia. Emprendieron el viaje y dixeron las missas y sucedió puntualmente todo lo que el alma avía dicho y prometido, con esta diferencia: que en las missas (a que assistieron también dos religiosos nuestros) se apareció el alma con vestiduras sacerdotales como las del sacerdote que dize missa.

1258. Dichas d'esta manera las dos missas que avía dicho el muchacho, y encomendado a otra persona que continuasse la ofrenda del medio año, se bolvieron a su casa pensando que con esto estava acabado aquel negocio y el ánima socorrida. Pero después de dos días se bolvió aparecer al mismo Bernardino, el qual le preguntó que quién era y qué quería. Respondiole que él era su tío, que no temiesse, que lo que quería era le dixessen sinco missas más que le faltavan en el mismo lugar que avían dicho las dos, y que la ofrenda se avía de hazer en la cathredal de Vique, y que su misma madre (del difunto) la avía de ofrecer. ${ }^{22}$ Esto dixo el alma, lo qual causó

${ }^{21}$ Para propiciar una nueva aparición, la familia sugiere a Bernardino que vaya a la planta superior. Esta distinción entre las partes baja y alta de la casa, que sin duda tiene una base antropológica, también juega un importante papel en el Procés d'Esperança Alegre, otro documento sobre apariciones, sucedido en Lleida en el año 1500, en el cual la visionaria, al contemplar horrorizada el espectro de ultratumba, desciende rápidamente por las escaleras hacia la planta baja: "y ella deposant ab gran espant y pahor cuytosament fugí e isqué de la dita cambra y se'n devallà en la entrada de dita casa, ha on na Violant Alegre, mare del dit Miquel Alegre, marit seu, ere; y quant baixave per dita escala, no abastant-li la força, se assentà en dita eschala y comptà ab grandíssim espant a sa sogre lo que li ere esdevengut" (Miró y Vila 1998: 341).

${ }^{22}$ El ánima de Sebastián recuerda a Bernardino lo que ya le había indicado en el primer diálogo entre ambos, pero, si entonces había advertido que la ofrenda de medio año debía hacerse 
mayores perplexidades: especialmente difficultavan que no bastasse el hazer la ofrenda por otro, sino que la misma madre la huviesse de hazer, porque era cosa bien dificultosa obligar a una pobre vieja ir a pie tres leguas de mal camino, que para su edad y pobresa era difícil jornada y trabajo grandíssimo el hazer la ofrenda y sustentarse medio año pidiendo limosna por las calles de Vique. Por lo qual hizieron que Bernardino le preguntasse al alma que por qué no avía pedido todas las missas de una vez. Al qual le respondió que ya ella se las avía pedido todas la primera vez, sino que él no lo avía bien entendido, pero que avía sido disposición divina, que por justas causas lo avía así querido.

1259. Visto esto por la madre, instó al muchacho que le bolviesse hablar y le pidiesse alguna señal en fe de lo que pedía. No lo reüsó el alma, tomándole luego la mano y haziéndole una cruz de fuego en la manga del braço derecho, la qual, aunque | ${ }^{399 a}$ passó toda la ropa, no le tocó en la carne, aunque la mano que le tomó el alma quedó como teñida de negro, que le duró algún tiempo ${ }^{23}$. Estando todavía incrédulo el hermano del difunto, al otro día por la mañana se bolvió aparecer el alma a Bernardino, el qual le preguntó si quería alguna otra cosa. Y le respondió que no quería otra cosa sino que fuessen tan presto como pudiessen a cumplir todo lo dicho, que le sacarían de mucha pena. Instó la madre del difunto al niño que le dixesse que en señal de que tenía harto con las sinco missas que pedía, hiziese otra señal al lado de la primera. Luego que se lo pidió, le cogió del braço y le hizo otra cruz en la manga, al lado de la otra, y en todo semejante a ella. Después de esto, pareciéndole al hermano del difunto que la mucha vejez de la madre la escusaría delante de Dios de ir a Vique a hazer la ofrenda, pensó un medio que la madre la hiziesse en la iglesia del lugar y otra persona la hiziesse también en Vique en el lugar que avía dicho el alma, creyendo píamente que con esto se cumpliría. Y así se empeçó a executar, pero presto se bolvió aparecer el alma, disiendo que quantas ofrendas avían hecho por él nada le avían aprovechado, porque Dios no avía querido acceptar ninguna d'ellas en su descargo; y que, en todo caso, bolviessen a enpeçar la ofrenda, porque era mucho lo que padecía. Desde entonces fueron más continuas las apariciones de la afligida alma. Cada día se aparecía tres y quatro vezes, repitiendo sus lástimas. No acabando todavía con esto de salir de sus dudas e incredulidad, quisieron ver otra señal. Pusieron una servilleta tendida sobre una mesa, diziéndole que hiziesse allí otra señal en confirmación de lo dicho. Y luego en el punto hizo en ella quatro cruzes de fuego. Añadieron entonces que, en señal que Bernardino avía de ir también a la ofrenda y asistir con su agüela, hiziesse otra cruz. Y luego la hizo debaxo las otras, con que quedó el lienço señalado con sinco cruzes, como oy día se ve. Y dixo el alma que los padresnuestros que le diría Bernardino le serían de grande alivio en sus penas. Y nótese que siempre se pareció a Bernardino, unas vezes con sobrepelliz y otras con casulla.

1260. Finalmente, se resolvieron de cumplir con todo y de la manera que lo pedía el difun-

en la iglesia donde estaba enterrado su cuerpo, ahora añade que debe ser en la catedral de Vic (cf. \1256). En ningún momento se confirma o se niega explícitamente que la iglesia en la que está enterrado sea catedral. Esta misma ambigüedad también afecta a la versión de fray Segismundo del Espíritu Santo copiada en el ms. 326 de la BUB.

${ }^{23}$ Diversos relatos nos hablan de la marca que deja un ánima de ultratumba en el cuerpo del visionario o en algún objeto, tal como sucede en algunos de los textos indexados en Thompson ([1932-1936] 1966: II, 475-476): "E542. Dead man touches living”. También pertenecen a esta modalidad algunas de las narraciones asociadas a Tubach ([1969] 1981: 89, núms. 1103-1104): “Cloak parchment"; "Cloak, stolen, masses for". Algunos de los testimonios y variantes de estos exempla explican cómo una gota de sudor del aparecido toca y perfora la mano del visionario como si se tratase de una flecha. Este caso ha sido estudiado por Berlioz (1985: 79), y cuenta con quince versiones incorporadas a ThEMA (2014), a las cuales podría añadirse el texto que transmite el Recull d'exemples, traducción catalana del Alphabetum narrationum: «E l'escolà dix: ‘[...] E no·t porie fer entendre quant foch qui·m crema soffir dejús aqueste capa de pergamí, però si volies acustar la tue mà a mi e que una gota de aquesta suor que jo pas te tocàs en la mà, ladonchs pories conèxer lo gran turment de foch que jo soffir.' E tentost lo maestre acostà la mà, en la qual li caech sola una gota de lla suor, la qual gota li passà la mà de l'altre part axí con si fos una segete o virató. E tentost l'escolà desperech" (Leodiensis 2004: 249-250, núm. 125). 
to. Emprendieron el viaje, y todo el camino les fue acompañando revestido como para dezir missa y con una vela en la mano, viéndolo solamente Bernardino ${ }^{24}$. En acercándose a alguna cruz, se adelantava hasta ella y allí en la cruz encendía la vela y, con ella, bolvía a acompañar sus peregrinos hasta que llegavan a la misma $\left.\right|^{399 b}$ cruz. Y así lo hazía en las demás cruzes, que no son pocas las de aquel camino. Continuando la ofrenda, se apareció también muchas vezes a Bernardino. En una d'ellas le dixo que fuessen muy agradecidos a Dios por averles manifestado todas aquellas maravillas; y que no tuviessen cuydado, que la ofrenda iva bien hecha y que ya no tendría necessidad de otra cosa, que en acabando el medio año se le aparecería en lo alto de una cruz rodeado de ángeles, con los quales se subiría al cielo y él la vería subir hasta que por la mucha distancia no la pudiesse ver. Estando después (ya muy adelantado el medio año de la ofrenda) Bernardino en su aposento, vino el alma acompañada de quatro ángeles hermosíssimos, dos a cada lado. Pusiéronse a conversar con el cándido niño y entre otras cosas le dixeron que tuviera cuenta que quando ellos se irían se abriría el techo y vería patente el cielo; y assí sucedió, viéndolos Bernardino que se subían volando hazia el cielo sin más tedio que si estuviera en un campo razo. Dexando otras cosas que passaron, por abreviar diré una más notable ${ }^{25}$. Apareciéndosele otra vez, le preguntó Bernardino que dónde avía passado el purgatorio y que por qué causa padecía. A lo qual respondió la bendita alma que siempre avía purgado junto a las casas donde avían vivido sus padres: "En Casa Nova — dixo- padecía debaxo un ribasso que avía alli cerca. En Casa de España, pené en un rincón de ella; y lo mismo en Casa Graell, ${ }^{26}$. A lo segundo dixo que padecía por un grande pecado que avía hecho "tomando la

${ }^{24}$ Fray Segismundo del Espíritu Santo da algunos detalles más sobre la indumentaria del difunto: "Por todo el camino les fue acompañando revestido siempre con los santos ornamentos que el sagrado ministro usa en la missa: amito, alba, manípulo, estola y casulla. En la mano trahía una vela" (BUB, ms. 326, fol. [9"], § 24).

${ }^{25}$ En este punto de la narración, añade fray Segismundo del Espíritu Santo otros breves episodios que, por su interés, transcribiremos a continuación: "En una de estas ocasiones que se le apareció el alma a Bernardino, le dixo dibuxase su rostro y figura de manera que se la havía $\mathrm{I}^{10 \mathrm{v}}$ mostrado, porque desseava y quería mucho que todo el mundo la creyesse y que tenía gran pena y dolor de los que murmuravan de aquello, como también de los que no querían creerlo. En esta conformidad sucedió poco después que, passando tres mujeres junto al susodicho Bernardino, dixo una de ellas: "Este es el muchacho a quien se apareció el alma". Respondió una: "Assí la ha visto él como yo", dando a entender no ser verdad que la huviesse visto, de lo qual aquella bendita alma mostró después mucho sentimiento y dixo a Bernardino que la havía dado mucha pena aquella muger con su incredulidad. Quiso después el muchacho, conforme a lo que le havía dicho el alma, dibuxar la belleza de su gracioso rostro de la manera que se le havía mostrado, y tomando la pluma tales cosas dibuxó en un papel que pasmavan a quantos miravan las celestiales sutilezas y primores que allí expressó el inocente niño en significación de lo que havía visto. Y si el descuydo de los que presentes se hallaron a esto no nos huviera privado de aquella delineación, pudiéramos ahora como por la uña rastrear algo del prodigioso león. Andava assí mismo solícita esta alma santa de que el niño viviesse muy ajustado, pues por haverlo sido assí siempre y de mucha candidez mereció verla. En conseqüencia de esto sucedió que, haviéndose resuelto en la vigilia de Navidad de comer antes de tiempo porque la hambre le molestava, al empezar la comida le quitó el alma el sombrero de la cabeza y lo puso encima de una tabla de la chimenea, avisándole con esto que no estava bien anticipar la hora de comer en día de ayuno, y más siendo de una festividad tan grande" (BUB, ms. 326, fol. [10 $\left.{ }^{r-v}\right]$, $\$ 27-28$ ).

${ }^{26}$ Esta concepción del purgatorio ligada al ambiente doméstico y, en todo caso, a la topografía terrenal tiene como idea de fondo la distinción entre dos purgatorios diferentes, uno general y otro particular, tal como prescribe Juan Gobi en su De spiritu Guidonis, cuando la voz de ultratumba que se escucha en la habitación del difunto adoctrina del siguiente modo: "Le purgatoire est double: commun et particulier [...] Je suis châtié dans la journée au purgatoire commun avec les autres âmes, et la nuit dans ce purgatoire particulier" (Gobi 1994: 81). Sobre esta creencia y su formulación por parte de los teólogos medievales, véanse Schmitt (1994: 177 y 206-207) y Mahiques Climent (2005: 11-13). 
limosna de tres missas — palabras son del difunto- que me avian encomendado para que las dixera en tal y tal día, y yo no las dixe en essos dias que me avian dicho. Y pensando que en otros dias las podría dezir, cai enfermo en la cama, con que no pude dezirlas, porque vino con esto la hora de la muerte. Y por este pecado he avido de penar tres años en el purgatorion. Aviéndole preguntado más, si ivan muchas almas al purgatorio, respondió que al purgatorio caen como quando llueve menudo, pero que al infierno como cuando nieva mucho, que los copos caen espesos. También le dixo que dixesse a su padre que él era el que le alumbró una noche escura, aviendo perdido el camino, y que en agradecimiento le rezasse un rosario entero cada día. Y dixo el padre que era verdad que en dicha ocasión vio una luz que, siguiéndola, bolvió a camino y hasta las primeras tapias del lugar, si bien él pensava que era algún otro hombre que iva delante con $\operatorname{luz}^{27}$.

1261. Llegado finalmente el penúltimo día de la ofrenda (que fue el mismo día de Pascua del Espíritu Santo), llegando a la noche, dixo Bernardino a sus agüelos que ${ }^{400 a}$ le despertassen tres horas antes de día ${ }^{28}$. Hiziéronlo assí y luego vio el muchacho dos velas encendidas en su aposento, sabiendo que nadie d'esta vida las avía puesto. En amaneciendo, se levantaron todos y quanto antes acudieron a hazer su última ofrenda. Hecha ésta y concluída la missa, se fueron muy aprisa a la cruz que está en el portal de la ciudad, llamado el Portal de Malloles, según el alma se lo avía dicho a Bernardino, que de allí se subiría al cielo. Luego que llegaron, vio Bernardino en lo alto de la cruz a su dichoso tío, el sobredicho licenciado Sebastián Roquero, ya muy alegre y resplandeciente, revestido con un precioso ornamento sacerdotal y con una capa pluvial hermosíssima ${ }^{29}$. Acompañávanle quatro ángeles con velas encendidas en las manos. Estando assí, levantó la mano y dio la bendición a todos los que allí presentes estavan y enpeçó a subirse con los ángeles con grande gloria, mirándolo Bernardino, hasta que por la mucha distancia le perdió de vista.

1262. Este es el caso, en que se pudieran ponderar muchas circunstancias utilíssimas si fuera de nuestra obligación, pero lo pueden y deven hazer todos los sacerdotes y prelados a quienes se encomiendan missas que dezir, para cumplir con ellas y con todas las circunstancias y condi-

${ }^{27}$ Ejemplos similares sobre la luz milagrosa son referidos en otros pasajes de los Annales de fray Juan de san José: "Al dexar el lugar de Villafranca enpeçó a faltar la luz y, no siendo los conductores bien prácticos de aquel paraje, perdieron el camino y vinieron a parar en un escabroso estrecho en medio de un bosque, donde fue preciso apearse de los coches con tanta falta de luz como sobra de congojas y de peligro. Mientras despacharon dos peones a buscar el lugar y traer luzes, aumentava la afflicción de las religiosas el destemple de los cocheros y moços de mulas que con desesperados juramentos y maldiciones horrorizavan más sus oýdos y coraçones que las tinieblas de la noche sus ojos. Enpeçaron a clamar al cielo y pedir socorro en tanta necessidad a la Virgen santíssima y a nuestro padre san Joseph. Estando en esta perplexidad congojosa y tan a escuras que apenas se percibían unos a otros, de repente se vieron rodeados de una luz tan clara como la reflexión que haze la de la luna quando yere la superficie del mar. Tan admirados como agradecidos, todos alabaron a Dios y caminaron alegres mucho rato gozando de la maravilla" (BUB, ms. 991, p. 459 b $\$$ 1425); "Yendo camino, una noche se escureció tanto que no veýa el camino ni dónde ponía los pies. Y con tanto temor de las bestias fieras que se encomendava muy de veras a la Virgen. Empeçó a ver delante de sí un resplendor que le guiava. Y le guió todo el camino que passó dando gracias a Dios y a la santíssima Virgen. Y este prodigio no le sucedió solo esta noche, sino otras también" (BUB, ms. 991, p. 688, \ 2151). La milagrosa luz que guía al extraviado va asociada a los difuntos en la Messe pour les ames du Purgatoire, que su protagonista, la viuda Blateyron, explicó en 1921 a Henri Pourrat (1989: 373-374).

${ }^{28} \mathrm{La}$ ofrenda se cumple, pues, en la fiesta de Pentecostés, que en el año 1681 caía el día 25 de mayo, según indica Cappelli (1930: 66).

${ }^{29}$ Fray Segismundo del Espíritu Santo refiere este pasaje del siguiente modo: "Luego que llegaron a ver aquella santa cruz, vio Bernardino a la bendita alma vestida ya de ropas immortales y de trage muy diferente que otras vezes, porque además de las vestiduras sagradas y sacerdotales trahía una capa pluvial o pontifical (que el niño llamava professonal, porque los curas la visten en las processiones) de incomparable belleza y hermosura" (BUB, ms. 326, fol. [11"], $₫ 32$ ). 
ciones que las admitieron, viendo que la omissión o descuydo de tres missas se paga con tres años de purgatorio. Y me persuado que para este fin (porque debe aver muchos descuydos d'estos, y no deven tener algunos la devida ponderación d'ellos) permitió nuestro Señor este caso tan público, circunstanciado y con tan multiplicadas apariciones y señales, y que para su perpetua memoria quedasse el sobredicho lienço con las sinco cruzes de fuego. Y para este mismo fin lo he escrito yo también de buena gana, para que se estienda más su noticia. En la verdad del caso no se puede dudar, porque Joseph Roquero, hermano del difunto, que asistió a todo, lo fue escriviendo assí como passava y, después de unos diez años, dio la dicha relación a un religioso nuestro que aún vive, el qual, con mucho cuydado, preguntas y repreguntas, le examinó al dicho Joseph y a otros de los que asistieron al caso y con juramento afirmaron ser assí verdad como se ha dicho, y halló ser essa la común voz y fama por aquella tierra ${ }^{30}$. El dicho lienço lo detuvo este convento, porque los padres y el hermano del difunto se lo dieron agradecidos a la asistencia que les hizieron los religiosos en todo el processo del referido caso, y por aver asistido al difunto en su enfermedad y muerte, y por la grande devoción que el mismo difunto los tuvo en vida, con- $\left.\right|^{400 b}$ fesándose siempre que podía con nuestros religiosos. No lo sintieron poco los de la cathedral no quedarse con la prenda, que no poco la solicitaron.

\section{BIBLIOGRAFÍA CITADA}

Amades, J. 1950-1969. Folklore de Catalunya. 3 vol. [I: Rondallística; II: Cançoner; III: Costums i creences]. Barcelona: Selecta.

Annuaire 1909. Annuaire statistique, historique et administratif du département de l'Orne pour 1909, avec carte du département, gravures et tableau. Alençon: Imprimerie de la Préfecture et des autres Autorités.

Arnall Juan, M. J. 1986. "Aportación de los carmelitas descalzos a la cultura catalana", en El Carmelo teresiano en Cataluña. 1586-1986: 55-108. Burgos: Monte Carmelo.

Baughman, E. W. 1966. Type and Motif-Index of the Folktales of England and North America. La Haya: Mouton \& Co.

Berlioz, J. 1985. "Virgile dans la littérature des exempla (XIII ${ }^{\mathrm{e}} \mathrm{XV}$ e siècles)", en Lectures médiévales de Virgile. Actes du colloque organisé par l'École française de Rome (25-28 octobre 1982): 65120. Roma: École Française de Rome / Palais Farnese.

Borbone, S. de 2002. Tractatus de diversis materiis predicabilibus. Prologvs. Prima pars de dono timoris. Cura et studio: Jacques Berlioz et Jean-Luc Eichenlaub. Turnhout: Brepols.

Cabal, C. 1921. Los cuentos tradicionales asturianos. Madrid: Voluntad.

Camarena, J. y Chevalier, M. 1995. Catálogo tipológico del cuento folklórico español. Cuentos maravillosos. Madrid: Gredos.

${ }^{30}$ Ya hemos indicado que este capítulo de los Annales toma como fuente la relación que fray Segismundo del Espíritu Santo redactó en 1691, unos diez años después del caso, según indica él mismo en el juicio personal que añade al final de la narración: "Esta en substancia es la relación del hecho que el hermano del difunto escrivió assí como iva passando, y asistió siempre a dicho Bernardino en todo lo referido. Los dos que arriba se nombraron viven aún y yo los conozco muy bien: $\left.\right|^{12 r}$ gente sincera y en quienes no se halla doblez ni engaño, y de costumbres muy loables y christianas como es notorio, voz común y fama pública. Los he tratado y examinado acerca del caso, en especial al que lo escribió, haziéndole las preguntas y repreguntas que juzgué ser convenientes para apurar la verdad. Hízele explicar su relación palabra por palabra y, después de haverla puesto en la forma que yo aquí la doy, se la volví a leer y depuso debaxo de juramento ser aquella la substancia del hecho y todo muy conforme a lo que havía pasado, de forma que menos la solemnidad del derecho, que se omitió por dificultades que trahen gastos y diligencias, no se podían hazer mayores en el caso presente aunque huviera de servir para la canonización de un santo. Hoc meum judicium, quod si opus esset juramento firmarem. Dat. Barcinonae in hoc nostro conventu Sancti Joseph Carmelitanum excalceatorum, die 4 Decembris

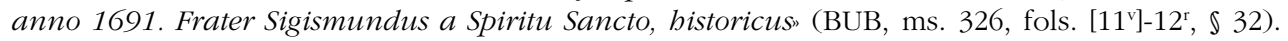


Camarena, J. y Chevalier, M. 2003. Catálogo tipológico del cuento folklórico español. Vol. 3-4 [III: Cuentos religiosos; IV: Cuentos-novela]. Alcalá de Henares: Centro de Estudios Cervantinos.

Cappelli, A. 1930. Cronologia, cronografia e calendario perpetuo dal principio dell'Êra cristiana ai nostri giorni. Milán: Ulrico Hoepli.

Carnoy, E. H. 1883. Littérature orale de la Picardie. París: Maisonneuve.

Charron, V. 1637. Kalendrier historial de la glorievse Vierge Marie Mère de Diev, faisant mention chaqve iour de l'an de quelque chose qui la regarde. Nantes: Pierre Doriou.

Coll, P. 2001. Quan Judes era fadrí i sa mare festejava. Rondalles de Pallars. Barcelona: La Magrana.

De Soland, A. 1858. "Le gantier de la rue Baudrière". Bulletin Historique et Monumental de l'Anjou, par Aimé de Soland. Cinquième année de la publication: 189-192. Angers: Imprimerie de Lainé Frères.

Espinosa, A. M. 1946. Cuentos populares españoles recogidos de la tradición oral de España. Madrid: Consejo Superior de Investigaciones Científicas / Instituto Antonio de Nebrija de Filología.

Fouquet, A. 1857. Légendes, contes et chanson populaires du Morbihan. Vannes: A. Cauderan.

Gobi, J. 1994. Dialogue avec un fantôme. Dossier établi, traduit et annoté par Marie-Anne Polo de Beaulieu. Préface de Jean-Claude Schmitt. París: Les Belles Lettres.

Jiménez Romero, A. 1990. La flor de florentena. Cuentos tradicionales recogidos en Arahal por Alfonso Jiménez Romero. Selección, introducción y notas de Melchor Pérez Bautista - Juan Antonio del Río Cabrera. Sevilla: Fundación Machado.

La Garde, M. 1858. Le val de l'Amblève. Histoires et scènes ardennaises par Marcellin La Garde. Tome second. Bruselas-Leipzig: Auguste Schnée.

La Vallée, J. y Brion, L. 1794. "Voyage dans les départemens de la France. Departement des Côtes-duNord». Fascículo núm. 38 de la serie entera y núm. 6 del vol. 5 de: Voyage dans les départemens de la France. Enrichi de Tableaux Géographiques et d'Estampes. Par les Citoyens J. La Vallée, ancien capitaine au $46^{e}$. régiment, pour la partie du Texte; Louis Brion, pour la partie du Dessin; et Louis Brion, père, auteur de la Carte raisonné de la France, pour la partie Geographique. París: Brion / Buisson / Desenne / Lesclapart / Directeurs de l'Imprimerie du Cercle Social.

Le Men, R. F. 1870-1872. "Traditions et Superstitions de la Basse-Bretagne". Revue celtique 1: 414-435.

Legendre, O. (ed.). 2005. Collectanevm exemplorvm et visionvm Clarevallense e codice Trecensi 946 edidit Olivier Legendre. Turnhout: Brepols.

Leodiensis, A. 2004. Recull d'exemples i miracles ordenat per alfabet. Volum I. Edició crítica de JosepAntoni Ysern Lagarda. Barcelona: Barcino.

Lisón Tolosana, C. 2004. La Santa Compaña. Fantasías reales. Realidades fantásticas. Madrid: Akal.

Lladonosa, J. 1967. "Llegendes lleidatanes. La darrera missa del capellà Marrades". Centro comarcal leridano. Boletín interior informativo 10/107: 5-6.

Mahiques Climent, J. 2005. "Lo somni de Bernat Metge i els tractats d'apareguts". Llengua E Literatura 16: 7-31.

Mahiques Climent, J. 2008. "Un fals aparegut en el Tirant lo Blanc". Caplletra. Revista internacional de filologia 44: 55-78.

Mahiques Climent, J. 2014a. "Tres carmelites descalços durant la pesta de Bellpuig: reescriptures d'un passatge historiogràfic". Urtx. Revista cultural de l'Urgell 28: 187-201.

Mahiques Climent, J. 2014b. «El relato folclórico del ánima del cura y la misa no celebrada en vida: versiones comparadas del dominio de Oïl. Anthropos. Internationale Zeitschrift für Völker- und Sprachenkunde 109 (en prensa).

Mahiques Climent, J. 2016. "Fray Pedro de Jesús en el purgatorio: reescrituras de un pasaje historiográfico" (en preparación).

MCEM 2012 = Duran, E. (dir.) y Toldrà, M. (coord.). MCEM (Base de dades de Manuscrits Catalans de l'Edat Moderna). Barcelona: Institut d'Estudis Catalans. http://mcem.iec.cat/ (Consultado 20/ 12/2012).

Miquel Rosell, F. 1958. Inventario general de manuscritos de la Biblioteca Universitaria de Barcelona. II: 501 a 1000. Madrid: Direcciones Generales de Enseñanza Universitaria y de Archivos y Bibliotecas.

Miró, R. y Vila, P. 1998. "Visió d'Esperança Alegre (Lleida, 1500). Una visita al més enllà", en Company, X. y Puig, I. (eds.), La pintura gòtica dels Ferrer i altres aspectes (in)coneguts al voltant de la Seu Vella de Lleida, s. XIII-XVIII: 327-353. Lleida: Amics de la Seu Vella. 
Oliveira, F. X. d'A. 1905. Contos tradicionães do Algarve. Vol. 2. Oporto: Typographia Burocratica e Typographia Universal.

Oriol, C. y Pujol, J. M. 2003. Índex tipològic de la rondalla catalana. Barcelona: Departament de Cultura (Generalitat de Catalunya).

Poulain, A. 1997. Sorcellerie, Revenants et Croyances en Haute-Bretagne. Rennes: Éditions OuestFrance.

Pourrat, H. 1989. Contes et récits du Livradois. Textes recueillis par Henri Pourrat. Edition établie par Bernadette Bricout. París: Maisonneuve et Larouse.

Pujol, J. M. 1982. Contribució a l'índex de tipus de la rondalla catalana. Tesis de licenciatura inédita. Dir. Dr. Jaume Vidal. Departament de Literatura Catalana: Universitat de Barcelona.

Redondo, A. 1997. "Las tradiciones hispánicas de la "Estantigua" "Cacería Salvaje” o Mesnie Hellequin) y su resurgencia en el Quijote", en Otra manera de leer el Quijote. Historia, tradiciones culturales y literatura: 101-119. Madrid: Castalia.

Rodríguez López, J. 1910. Supersticiones de Galicia. 2a edición. Madrid: Imprenta de Ricardo Rojas.

Rondcat 2014 = Oriol, C. y Pujol, J. M. Rondcat. Cercador de la rondalla catalana / Catalan Folktales Search Engine / Buscador del cuento folclórico catalán / Moteur de recherche des contes populaires catalans. Tarragona: Arxiu de Folklore (Universitat Rovira i Virgili, Departament de Filologia Catalana). http://www.sre.urv.cat/rondcat (Consultado 09/05/2014).

Sauvage, H. 1869. Légendes normandes recueillies dans l'arrondissement de Mortain (Manche) par M. Hippolyte Sauvage, juge de paix du canton du Louroux-Bécconaix. Deuxième édition. Angers: Imprimerie P. Lachèse, Belleuvre et Dolbeau.

Schmitt, J-C. 1994. Les revenants. Les vivants et les morts dans la société féodale. París: Gallimard.

Sébillot, P. 1900. Légendes locales de la Haute-Bretagne. Deuxième partie: l'histoire E la légende. Nantes: Société des Bibliophiles Bretons.

Sébillot, P. 1907. Le folk-lore de France, par Paul Sébillot. Tome quatrième: le peuple et l'bistoire. Avec une table analytique et alphabétique. París: Livrairie Orientale \& Américaine.

ThEMA 2014 = Berlioz, J.; Polo de Beaulieu, M. A. y Collomb, P. (dirs.). Thesaurus Exemplorum Medii Aevi (ThEMA). París: École des Hautes Études en Sciences Sociales. http://lodel.ehess.fr/ gahom/thema (Consultado 08/05/2014).

Thompson, S. [1932-1936] 1966. Motif-Index of Folk Literature. A classification of Narrative Elements in Folktales, Ballads, Miths, Fables, Mediaeval Romances, Exempla, Fabliaux, Jest-books and Local Legends, 6 vol. Bloomington-Londres: Indiana University Press. [1a edición: 1932-1936. 2a edición, revisada: 1955-1958].

Tubach, F. C. [1969] 1981. Index exemplorum. A handbook of medieval religious tales. Helsinki: Suomala Tiedeakatemia / Academia Scientiarum Fennica.

Uther, H.-J. 2004. The types of international folktales. A Classification and Bibliography. Based on the System of Antti Aarne and Stith Thompson. Editorial Staff: Sabine Dinslage, Sigrid Fährmann, Christine Goldberg, Gudrun Schwibbe, 3 vol. Helsinki: Suomalainen Tiedeakatemia / Academia Scientiarum Fennica.

Fecha de recepción: 1 de octubre de 2013

Fecha de aceptación: 17 de mayo de 2014 